\title{
A concepção histórica da Educação de Jovens e Adultos no estado de Roraima-Brasil.
}

(The historical conception of Youth and Adult Education in the state of RoraimaBrazil.)

Ana Maria da Silva Rodrigues

Universidad Autónoma de Asunción (UAA)-Paraguay

Fecha recepción: 01-08-2018

Páginas 01-15

Fecha aceptación: 30-09-2018

\section{Resumo.}

Este artigo faz um breve relato dos principais acontecimentos ao longo da história da Educação de Jovens e Adultos no Estado de Roraima. A Educação de Jovens e Adultos (EJA) no Brasil ainda é tida uma modalidade de ensino em um campo específico de política pública educacional todavia recente a partir da Lei de Diretrizes e Bases da Educação Nacional 9394/96. Assim, se buscou evidenciar enquanto objetivo principal a trajetória da EJA, as lutas e as tentativas de mudanças. No entanto, Roraima, tem travado luta constante, marcada por conquistas, bem como, recuos, devido a vários projetos e muitas vezes sem o tempo necessário para que surtissem efeitos e consequentemente foram derruídos ou trocados por novos projetos. Deste modo pode-se dizer que o cenário atual, ainda há muito para se conquistar, transpor as mudanças de paradigmas alienadores a tão almejada obtenção de cidadãos pensantes, atuantes, críticos e ativos na sociedade latente.

Palavras-chaves: história; trajetória; educação; jovens; adultos

\begin{abstract}
.
This article gives a brief account of the main events throughout the history of Youth and Adult Education in the State of Roraima. The Education of Young Adults and Adults (EJA) in Brazil is still considered a modality of education in a specific field of public education policy, however recent, based on the National Education Guidelines and Bases Law 9394/96. Thus, it was sought to highlight as main objective the trajectory of the EJA, the struggles and the attempts of changes. However, Roraima has been fighting constant, marked by achievements, as well as setbacks, due to several projects and often without the time needed for them to come to fruition and consequently were destroyed or exchanged for new projects. In this way, it can be said that the current scenario, still has much to conquer, to transpose the changes of alienating paradigms to the longed for obtaining citizens thinking, active, critical and active in the latent society.
\end{abstract}

Keywords: history; trajectory; education; young; adults 


\section{1.-Introdução.}

Este trabalho aborda os principais acontecimentos na trajetória da Educação de Jovens e Adultos (EJA) no Estado de Roraima.

Para sua elaboração, realizaram-se pesquisas de cunho bibliográfico e documental, acerca da evolução histórica da EJA no decorrer dos anos. Entretanto, o objetivo geral buscou evidenciar a trajetória da Educação de Jovens e Adultos (EJA) as lutas e as tentativas de mudanças.

Uma vez que a ação educativa de jovens e adultos no Brasil vem de longa data desde o período colonial, os religiosos exerciam ações educativas missionárias em grande parte com adultos. Com 0 advento da Constituição de 1891 primeiro marco legal da República brasileira consagrou-se uma concepção de federalismo em que a responsabilidade pública pelo ensino básico foi descentralizada nas Províncias e Municípios. Até esse período, a preocupação com a educação de jovens e adultos praticamente não se distinguia como fonte de um pensamento pedagógico ou de políticas educacionais específicas. Foi somente ao final da década de 1940 que a educação de adultos veio a se firmar como um problema de política nacional.

Como se pode constatar o campo da educação de jovens e adultos no Brasil tem uma longa história, todavia, a configuração da (EJA) enquanto modalidade de ensino como um campo específico de política pública educacional é bastante recente, após a aprovação da Lei de Diretrizes e Bases da Educação Nacional № 9394/96, a qual regulamenta o sistema educacional (público e privado) do Brasil (da educação básica ao ensino superior). No seu artigo $37^{\circ}$ inciso $1^{\circ}$ é realçado que o público da EJA, ou seja, todos aqueles que não conseguiram completar seus estudos no ensino regular, tem direito à gratuidade e oportunidades educacionais em todos os sistemas de ensino, respeitando as suas características, situação de vida e de trabalho, através de cursos e exames.

No Estado de Roraima, a (EJA) surgiu na década de 1940 no governo de Ene Garcez, após fazer o levantamento das necessidades básicas do recém-criado Território. Dentre as várias medidas após sua posse, com vistas no desenvolvimento da região, fomentou-se a necessidade do ensino profissional (Santos, 2000). Isto já demonstrava preocupação com a prioridade na ação educativa.

Embora, com o passar dos anos, tenham sido implementadas ações e programas destinados à Educação Básica em Roraima particularmente criados para 0 combate ao analfabetismo no Estado foram precipitados, isso porque $s$ isso porque se elaborava vários projetos e muitas vezes, não havia tempo necessário para surtirem efeitos e consequentemente eram derruídos ou trocados por novos projetos. 


\section{2.-Contextualização Histórica da Educação e Jovens e Adultos no Brasil.}

É fato que a EJA não é algo recente, mas para falar de sua trajetória no estado de Roraima é de fundamental importância abordar o caminho percorrido desse campo educativo no território nacional. Segundo Haddad \& Di Pinheiro (2000, p. 108):

"No período colonial os religiosos exerciam sua ação educativa missionária em grande parte com adultos. Além de difundir o evangelho, tais educadores transmitiam normas de comportamento e ensinavam os ofícios necessários ao funcionamento da economia colonial, inicialmente aos indígenas e, posteriormente, aos escravos negros".

No entanto, foi a Constituição de 1891, o primeiro marco legal da República brasileira, a qual consagrou uma concepção de federalismo em que a responsabilidade pública pelo ensino básico foi descentralizada nas Províncias e Municípios. Já a partir da década de 1920, o movimento de educadores e da população em prol da ampliação do número de escolas e da melhoria de sua qualidade começou a estabelecer condições favoráveis à implementação de políticas públicas para a educação de jovens e adultos. Foi somente ao final da década de 1940 que a educação de adultos veio a se firmar como um problema de política nacional.

A constatação de altos índices de analfabetismo no país, em 1940, levou o governo a criar um fundo destinado a alfabetização da população adulta analfabeta. Cinco anos após, com o final da ditadura de Vargas, iniciou-se um movimento de fortalecimento dos princípios democráticos no pais que culminou em 1947 com o lançamento da Campanha de Educação de Adultos, propondo alfabetizado aos adultos do país, dentro de um período de três meses, pois o analfabetismo era visto como causa (e não como efeito) e o adulto analfabeto era identificado como elemento incapaz e marginal psicológica e socialmente, submetido a menoridade econômica, política e jurídica, não podendo, então, votar ou ser votado, como afirma Cunha (1999). As pessoas oriundas dos cursos de alfabetização poderiam ingressar no curso primário, que acontecia em duas etapas de sete meses.

Em 1967, o governo assume o controle dos Programas de Alfabetização de Adultos, tornando-os assistencialistas e conservadores. Neste período, foi implantado 0 Movimento Brasileiro de Alfabetização MOBRAL, sendo expandido, na década de 70, por todo o território nacional, diversificando sua atuação. Era um curso baseado nas ideias de Paulo Freire e seu objetivo era erradicar o analfabetismo do Brasil. Entretanto, por ser um programa federal, não era subordinado ao governo do então Território Federal de Roraima e tinha sua execução desvinculada da Secretaria de Educação. Do MOBRAL derivaram outras iniciativas, dentre as quais a mais importante foi o Programa de Educação Integrada (PEI) sendo uma forma condensada do antigo curso primário. Em 1985, o MOBRAL, desacreditado, foi extinto e seu lugar foi ocupado pela Fundação Educar, que apoiava, financeira e tecnicamente, as iniciativas do governo, das entidades civis e das empresas. 
A partir da década de 1980 e 1990, a educação deixou de ser um ensino voltado para a prática tradicional, fazendo com que os educadores buscassem novas propostas de ensino, com intuito de ajudar no crescimento do aluno para um ensino mais qualificado e consequentemente um futuro melhor para humanidade. A Constituição Federal de 1988 deixa bem claro em seu artigo 205 ao 214 a forma como a educação nacional deverá ser desenvolvida. No seu Art. 208 é estabelecido que:

Art. 208, diz que é dever do Estado a educação sendo efetivado mediante a garantia: I.-Educação básica obrigatória e gratuita dos 4 (quatro) aos 17 (dezessete) anos idade, assegurada inclusive sua oferta gratuita para todos os que a ela não tiveram acesso na idade própria; (Redação dada pela Emenda Constitucional $n^{\circ} 59$, de 2009); Vl:-Oferta de ensino noturno regular, adequado às condições do educando.

Com a extinção de a Fundação Educar na década de 90, cria-se um enorme vazio na Educação de Jovens e Adultos, ficando a critério dos Estados e Municípios a opção de assumir a responsabilidade de oferecer programas de Educação de Jovens e Adultos.

Por isso a história da Educação de Jovens e Adultos no Brasil chega à década de 90 reclamando reformulações pedagógicas. Ainda na mesma década, o governo omitiuse da articulação da política nacional de EJA, incumbindo aos municípios esta atividade. Surgiram inúmeras iniciativas e parcerias entre municípios, ONG's e Universidades. No final da década de 90, ocorreram vários encontros, congressos, seminários e conferências nacionais e internacionais sobre a Educação de Jovens e Adultos (EJA).

Surgem, nesse contexto, os Fóruns de EJA, como espaços para alternativos para as discussões das políticas de EJA no país. Segundo Soares (2004). Os Fóruns são movimentos que articulam instituições, socializam iniciativas e intervêm na elaboração de políticas e ações da área de EJA. Estes ocorrem num movimento nacional, com 0 objetivo de interlocução com organismos governamentais para intervir na elaboração de políticas públicas.

Com o surgimento dos Fóruns a história da EJA passa a ser registrada num Boletim da Ação Educativa, que socializa uma agenda dos Fóruns e os relatórios dos Encontro Nacionais de Educação de Jovens e Adultos - ENEJAS

A Lei de Diretrizes e Bases da Educação (LDB) n 9394/96, inclui a EJA como modalidade da Educação Básica e dedica especificamente dois artigos, 37 e 38 respectivamente, que reafirmam a obrigatoriedade e a gratuidade da oferta da educação para todos que não tiveram acesso na idade própria e define como público àqueles que não tiverem acesso ou continuidade de estudos no Ensino Fundamental e Médio na idade própria. 
Em 2000, sob a coordenação do Conselheiro Carlos Roberto Jamil Cury, é aprovado o Parecer $n^{\circ} 11 / 2000$ CEB/CNE, que trata da A LDB (Lei de Diretrizes e Bases) $n^{\circ}$ 9.394/96 no que se refere à Educação de Jovens e Adultos em seu Artigo $3^{\circ}$ determina dentre os princípios que devem servir de base ao seu ensino os seguintes: "Igualdade de condições para o acesso e permanência na escola [...] Pluralidade de ideais e de concepções pedagógicas, [...] garantia de padrão de qualidade, [...] valorização da experiência extraescolar, [...] vinculação entre a educação escolar, 0 trabalho e às práticas sociais".

O Plano Nacional de Educação (PNE), instituído pela lei $n^{\circ} 10.127 / 01$, reflete 0 diagnóstico com base nos dados da última década do século passado e estabelece as diretrizes, objetivos e metas para etapas e modalidades da educação, para 0 decênio 2001 a 2010, em consonância com a Declaração Mundial sobre Educação para Todos (1990).

Em 13 de fevereiro de 2003, a UNESCO instituiu a Década das Nações Unidas para a Alfabetização, delimitando-a no período compreendido entre 2003 a 2012, como mais um impulso em direção ao direito à "Educação para Todos". Como decorrência, no Brasil, em 2003, é lançado outro programa federal denominado Programa Brasil Alfabetizado, com a missão de abolir 0 analfabetismo.

O Ministério da Educação, para enfrentar os processos excludentes que marcam os sistemas de educação no país, cria, em 2004, a Secretaria de Educação Continuada, Alfabetização e Diversidade (SECAD). Respeitar e valorizar a diversidade da população, garantindo políticas públicas como instrumentos de cidadania e de contribuição para a redução das desigualdades são os objetivos desta nova Secretaria.

No governo Luís Inácio Lula da Silva (2003-2010), ocorre à expansão da educação profissional. Neste governo passou-se a mencionar a alfabetização de jovens e adultos como área de interesse prioritário, incorporaram-se as matrículas ao financiamento do FUNDEB e desenvolveram-se várias inciativas distribuídas em diferentes Ministérios no período compreendido entre 2002 a 2006 voltadas os jovens e adultos trabalhadores. Entre estas destacam-se: Brasil Alfabetizado, Saberes da Terra, Proeja, Escola de Fábrica, Exame Nacional para Certificação de Competências de Jovens e Adultos, ENCEJA, Consórcio Social da Juventude, Juventude Cidadã, Plano Nacional de Qualificação, A gente Jovem, Soldado Cidadão, Programa Nacional de Educação na Reforma Agrária, PRONERA, PROEP (Ministério da Educação e Ministério do Trabalho), Plano Nacional de Qualificação, PNQ (MTE), Projeto de Profissionalização dos Trabalhadores da área de Enfermagem - PROFAE (Ministério da Saúde), Programa de Assistência e Cooperação das Forças Armadas à Sociedade Civil/Soldado Cidadão (Ministério da Defesa).

Na tentativa de integrar a educação profissional à educação básica na modalidade de Educação de Jovens e adultos, criou-se o PROEJA, instituído como programa 
educacional brasileiro pelo Decreto $n^{\circ} 5.840$, de 13 de julho de 2006 para todas as esferas de ensino estadual, municipal e federal. Vale ressaltar que esse Decreto deriva de uma ampliação do Decreto 5.478 de 24 de junho de 2005, que criou 0 Programa, mas, no entanto, limitava sua extensão ao âmbito das instituições federais de educação tecnológica e ao nível médio.

O Proeja configura-se como uma proposta inédita no Brasil, no sentido da oferta da Educação de Jovens e Adultos (EJA) integrada à formação profissional. Seus objetivos são de inclusão social por meio da capacitação para 0 trabalho acompanhada de elevação da escolaridade.

O Projeto de Lei do Plano Nacional de Educação 2011-2020, aprovado pela Lei $n^{0}$ 13.005, de 25 junho de 2014, continua a propor as mesmas finalidades para a EJA, destacando na meta 9 que o objetivo é elevar a taxa de alfabetização da população com 15 anos ou mais para 93,5\% até 2015 e erradicar, até 2020, o analfabetismo absoluto e reduzir em $50 \%$ a taxa de analfabetismo funcional. O PNE estabelece como estratégias assegurar a oferta gratuita da educação de jovens e adultos a todos os que não tiveram acesso à educação básica na idade própria e implementar ações de alfabetização de jovens e adultos com garantia de continuidade da escolarização básica.

Atualmente o Plano Nacional de Educação 2014-2024 traz dez diretrizes, entre elas a erradicação do analfabetismo, a melhoria da qualidade da educação, além da valorização dos profissionais de educação, um dos maiores desafios das políticas educacionais. De acordo com 0 art. $7^{\circ}$ dessa nova lei, a União, os estados, o Distrito Federal e os municípios atuarão em regime de colaboração para atingir as metas e implementar as estratégias previstas no texto Meta 10 é "oferecer, no mínimo, 25\% das matrículas de educação de jovens e adultos, nos ensinos fundamental e médio, na forma integrada à educação profissional".

\section{1.-A Educação de Jovens e Adultos (EJA) no Contexto Histórico de Roraima.}

O Estado de Roraima está localizado no extremo norte do Brasil. Seus limites são os seguintes: Venezuela (Norte e Noroeste); Amazonas (Sul e Oeste); Guiana (Leste); Pará (Sudeste). A extensão territorial de Roraima é de 224.298,980 km², divididos em 15 municípios. Roraima é o estado com a menor população do Brasil. A capital do estado é Boa Vista, como mostra a imagem abaixo. 
Figura 1: Mapa do Estado de Roraima.

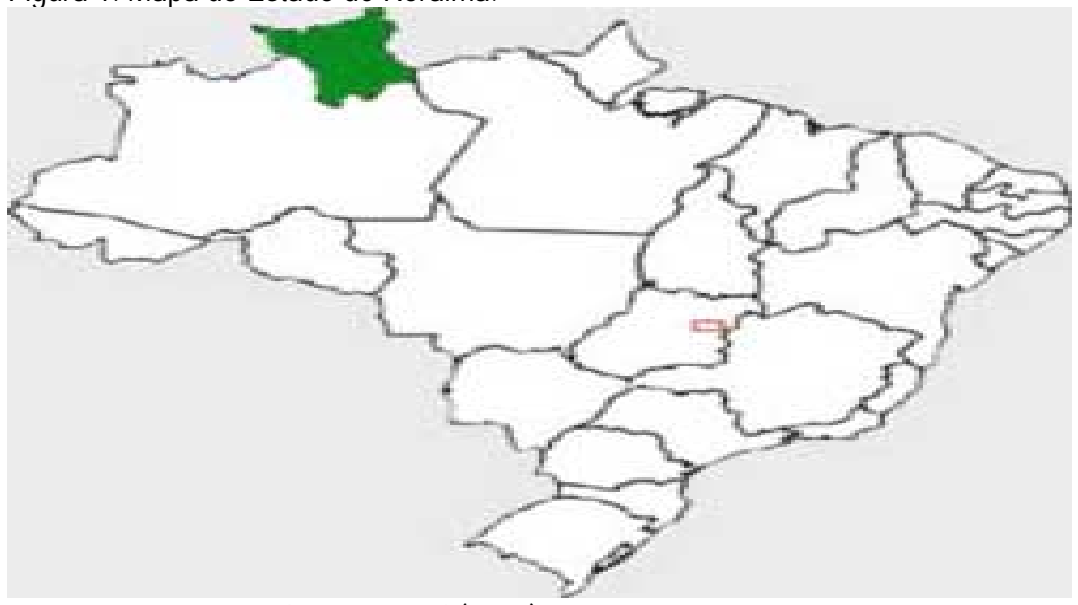

Fonte: Direitos H. Marketing Digital (2008).

O antigo território do Rio Branco (atualmente Roraima) foi disputado por espanhóis, portugueses, holandeses e ingleses desde o início do século XVI. Seu povoamento só começou no século XVIII, após o extermínio de grande número de indígenas. 0 capitão Francisco Ferreira e o padre carmelita Jerônimo Coelho foram os primeiros colonizadores a chegarem ao rio Branco. Seus propósitos eram aprisionar índios e recolher ovos de tartaruga para a produção de manteiga.

Já a criação do Território Federal do Rio Branco foi pelo Decreto-lei n 5.912 de 13 de setembro de 1943 (Freitas, 1993, p. 22; Santos 2004, p. 89;), no Governo de Getúlio Vargas em plena Segunda Guerra Mundial, e em "nome da segurança nacional", foram criados pelo mesmo decreto lei os territórios do Amapá, Fernando de Noronha, do Guaporé, de Ponta-Porã e do Iguaçu. O território Federal do Rio Branco, como os demais que foram criados, necessitava de uma infraestrutura para chamar à vida a imensa região Amazônica, o que implicava agir em várias frentes: Engenharia e obras; educação e cultura; Saúde e Saneamento; Organização e fomento da produção; Terras, colonização e transporte (Freitas, 1993, p.26).

Segundo Freitas (1993), a História do Território Federal do Rio Branco dividiu-se em três fases: A primeira fase envolve o período da criação, de 1943 até 0 golpe Militar em 1964, este primeiro momento, é caracterizado pela implantação da infraestrutura básica para o funcionamento da administração local. A primeira fase da história do Território do Rio Branco é marcada pela falta de instabilidade política caracterizada, pelas disputas políticas entre as elites locais (Freitas, 1993). Teve início as escolas públicas, as quais organizaram em nível municipal e/ou territorial. Assim foram construídos os chamados grupos escolares. E os primeiros cursos preparatórios para os professores.

A Educação em Roraima teve seu início entre com o povo indígena. Inicialmente com o missionário evangélico Thomas Yound por meio do cristianismo, mas ele foi 
expulso do território pelos indígenas. Entre 1943 e 1964, o território Federal do Rio Branco foi governado por quinze governadores; a segunda fase é marcada pelo grande crescimento populacional deste período. Em 1943, o Território possuía uma população de 19.709 mil habitantes, sendo que os indígenas representavam 70\% da população.

A segunda fase insere-se no período dos governos dos militares, de 1964 até 1985, agora como Território Federal de Roraima, pois em 13 de setembro de 1962, o nome do Território Federal do Rio Branco foi substituído por Território Federal de Roraima, compondo o "espaço de segurança nacional" dentro da geopolítica dos militares. Toda esta doutrina tinha sentido no "calor" da Guerra Fria (Feitoza, 2008). Foi nesse período que os governadores (todos eles oficias de alta patente da Aeronáutica até 1983) ficaram mais tempo no comando político em relação à primeira fase histórica do Território do Rio Branco.

A terceira e última fase, envolve o período de 1985, com a presença de vários governadores civis até 1991, com a posse do primeiro governado eleito Ottomar de Sousa Pinto, que inauguraria a atual fase de mais um estado da federação nacional (pela constituição de 1988, o estado foi criado, mas que só se tornaria um Estado de fato com a posse do governador eleito pelo voto popular).

O governador Ene Garcez, após fazer o levantamento das necessidades básicas do recém-criado Território, adotou várias medidas após sua posse com o objetivo de desenvolver a região, além da infraestrutura necessária ao funcionamento da estrutura administrativa, fomento à pecuária e agricultura, a segurança pública, a saúde e a necessidade do "ensino profissional" (Santos, 2000, p.59). Isto já demonstrava preocupação com a prioridade na ação educativa. Ainda segundo Santos (2000), o projeto de desenvolvimento econômico e social do Território, além da infraestrutura, exigiu-se a contribuição na "execução de um plano educacional" capaz de possibilitar a viabilidade dos projetos.

Em 1947, após apenas três anos de criação, o território Federal do Rio Branco tinha 16 escolas. Segundo Macêdo (2010), entre essas escolas existentes funcionavam "as escolas supletivas noturnas". E para mostrar que educação de qualidade, implica na qualificação dos docentes, o segundo governador Clóvis Nova da Costa, no ano de 1947 envia duas professoras normalistas para que "fizessem um curso de aperfeiçoamento, sob a orientação do INEP" (Macêdo, 2010, p.243).

Mas o primeiro curso que funcionou voltado para a Educação de Jovens e Adultos, teve início em 1948, no prédio da Escola Lobo D'Almada, com o nome de Escola Supletiva Noturna. Atendia a alunos de $1^{\mathrm{a}}$ a $4^{\mathrm{a}}$ série do Curso Primário, como era denominado. Funcionava com aulas presenciais e tinha a mesma estrutura das séries do Ensino Regular. Seu objetivo era preparar os alunos para um exame anual por série. A partir de 1951, passou a chamar-se "Curso Lourenço Filho" e funcionou no mesmo prédio da Escola Lobo D'Almada, até 1972. O Com o advento da Lei 5692/71 (Lei de Diretrizes e Bases), o sistema supletivo de 0 ensino foi implantado 
em todo país, em forma de cursos e exames, atendendo a um O contingente cada vez maior de adultos, a cada ano.

O primeiro curso voltado para a clientela analfabeta foi o Movimento Brasileiro de Alfabetização MOBRAL, que é quando a Educação de Jovens e Adultos em Roraima ganha uma nova configuração a partir de 1972, é neste ano que começam os exames de suplência geral. Enquanto o MOBRAL agia na alfabetização das pessoas que nunca haviam frequentado uma sala de aula, os exames de suplência geral procuravam acelerar o processo de escolarização das pessoas.

Em 14 de maio de 1975, pela Resolução nº 01/75, pelo Conselho Territorial de Educação - CTE foi criado o primeiro Centro de Estudos Supletivos (CES). O referido centro funcionava no sistema modular, 0 aluno fazia sua matrícula na disciplina que ainda não tinha concluído, e após pegar os módulos para estudar em casa, 0 aluno retornava para fazer a prova no Centro de Estudos supletivos (CES) no bairro do São Francisco. O centro atendia inicialmente aos alunos maiores de 18 anos, no ensino de $5^{\mathrm{a}}$ a $8^{\mathrm{a}}$ séries. Em seguida, 0 atendimento foi estendido aos alunos do $2^{\circ} \mathrm{grau}$, conforme a Resolução nº5/75, que nos Arts. $1^{\circ}$ e $2^{\circ}$ expressava:

"Art. $1^{0}$ - Os exames de Suplência Geral serão realizados com o fim de habilitar ao prosseguimento de estudos em caráter regular.

Art. $2^{\circ}$.-Os Exames a que se refere 0 artigo anterior, deverão realizar-se:

a). A nível de conclusão do ensino de $1^{\circ}$ grau, para maiores de 18 anos ou a completar até a data da realização da primeira prova;

b). A nível de conclusão do ensino de $2^{\circ}$ grau, para maiores de 21 anos ou a completar até a data da realização da primeira prova".

Essa experiência de suplência geral foi implantada em 04 municípios de Roraima, que funcionou ente 1976 a 1990. Ainda na década de 80, o sistema modular foi implantado em cursos profissionalizantes como o Projeto Logos II, que visava habilitar professores leigos para atuarem no ensino fundamental (Roraima-Secad, 2010).

Outra ação desenvolvida foi o Projeto Minerva, curso de Suplência Geral no nível de $5^{a}$. a $8^{a}$. série, veiculado pelo rádio para todo o Estado, tendo 0 aluno que acompanhar as aulas com apoio de material impresso e ajuda de monitor capacitado para esse fim. $O$ projeto atravessou muitas dificuldades. A transmissão no rádio quase sempre era interrompida com problemas de recepção de sinais, e em algumas situações 0 aparelho de rádio não funcionava por falta de pilhas, alguns alunos não acompanhavam por situação de surdez ou porque lhes faltavam pré-requisitos para a aprendizagem.

Objetivando a melhoria do atendimento aos alunos o Projeto Minerva foi substituído pelo Supletivo de $1^{\circ}$. Grau - SPG, que funcionava nos mesmos moldes do anterior, sendo que as aulas eram gravadas e ouvidas pelos alunos através de gravador portátil. 
Com a instalação da Rede Amazônica de Televisão, em Boa Vista, foi veiculado 0 primeiro curso supletivo televisivo o Projeto João da Silva, atendendo alunos de $1^{\mathrm{a}} \mathrm{a}$ $4^{\mathrm{a}}$ série.

A educação de jovens e adultos começa a viver uma crise existencial com a falência do MOBRAL na metade da década de 80, que é substituído pela Fundação Educar na década de 90 . Nesse período, os dois programas estavam na coordenação do Governo Federal. Diante do vácuo de ação educativa voltada para os jovens e adultos, cada estado e os municípios implantaram os projetos mais variados sobre a educação voltados para essa modalidade. Em Roraima foram implantados os seguintes projetos:

Posteriormente outras experiências foram vivenciadas, como por exemplo, 0 Programa Estadual de Teleducação para Ensino Médio (PETEM) e o Programa Estadual para o Ensino Fundamental (PETEF), aliado, a tele aulas, o material de apoio impresso e monitores treinados para acompanhar a aprendizagem dos alunos (Roraima-Secad, 2010)

Em 1990 foi implantado na Penitenciária Agrícola de Monte cristo, o programa Supletivo de Primeiro Grau, conhecido nacionalmente como SPG. Em 2001 foi implantado nos níveis de ensino fundamental e médio, um curso preparatório para os exames de Suplência Geral, desenvolvido através da Educação a Distância, utilizando material do Telecurso 2000, tendo sido interrompido, no ano de 2007.

A EJA em Roraima é estrutura em 2002, com a proposta de restauração dos cursos da Educação de Jovens e Adultos, por meio do parecer n ${ }^{0}$ 59/02 do Conselho Estadual de Educação- CEE/RR. Por esta proposta, as aulas para os alunos dessa modalidade passam a ser presencial, com avaliação semestral. Para a conclusão de uma série é ofertado uma avaliação nas escolas estaduais.

\section{2.-Resultados mais recentes sobre a Educação de Jovens e Adultos em Roraima.}

O Fórum Permanente de Debate da Educação de Jovens e Adultos em Roraima é criado em 2004 e visa a mobilização de toda sociedade roraimense em torno da educação, mais especificamente, da EJA. Em 2008, é criado pelo Decreto nº 8622-E, a Central de Atendimento e Registro (CAR). Esse centro tem a incumbência de coordenar a Educação de Jovens e Adultos nas escolas da capital e do interior de todo o estado de Roraima, bem como a realização do provão para o ensino médio.

Foi a partir de 2010 através da parceria entre a Secretaria de Educação Continuada, Alfabetização e Diversidade (SECAD), o Fundo Nacional de Desenvolvimento da Educação (FNDE) e o Governo do Estado de Roraima, através da Secretaria de Educação, Cultura e Desportos, que implantaram o Programa Roraima Alfabetizado, com objetivo de alfabetizar = jovens, adultos e idosos que não tiveram acesso ou permanência na escola em idade própria, oportunizando-os ao prosseguimento dos estudos no ensino fundamental. Atualmente a ação pedagógica e as políticas 
relacionadas à modalidade são desenvolvidos pela Secretaria Estadual de Educação e Desportos (SECD), com acompanhamento e avaliação do Departamento de Educação Básica, através da Divisão de Educação de Jovens e Adultos (DIEJA).

Em 2011, foi realizada a primeira Conferência de Educação do Sistema Prisional do Estado de Roraima, no Auditório da ex: Escola Estadual Barão de Parima, com objetivo de discutir as diretrizes nacionais para oferta da educação em estabelecimentos penais, tendo em vista, a necessidade de elaboração do Plano Estadual de Educação do Sistema Prisional de Roraima e discussão dos problemas locais da comunidade escolar e prisional.

Este evento teve como público alvo representantes da Secretaria de Educação, Cultura e Desportos do Estado de Roraima, Secretaria de Estado da Justiça e Cidadania, professores, gestores e agentes penitenciários, membros da sociedade civil, representantes de Fundações, Fórum da Educação de Jovens e Adultos, dos Conselhos de Educação Municipais e Estadual, Centro de Defesa dos Direitos Humanos, Órgãos responsáveis s pela Execução Penal, Ministério Público e Defensoria, Segmentos dos Ministérios da Educação e da Justiça.

Atualmente no Estado, a Escola Estadual Antônio Ferreira de Souza (EEAFS) é a única unidade de ensino que atua com EJA no sistema prisional e que terá que se adaptar às diretrizes nacionais para a área. A escola, além de atender o corpo discente da capital, também atende à demanda de alunos do sistema prisional, no Distrito de Monte Cristo.

Outro fator importante é que em Roraima, Conforme levantamento de dados da SECD-Roraima DIEJA (2011) há 78 (setenta e oito) unidades de ensino da rede estadual que atuam com EJA, distribuídas nos municípios e capital, como mostra 0 gráfico abaixo. Desse universo, 21,8\% atuam com comunidades indígenas, 30,8\% atuam na capital e $47,4 \%$ no interior.

\section{3.-Metodologia.}

Para melhor fundamentar esse trabalho a pesquisa documental bibliográfica com enfoque qualitativo acerca da evolução histórica da Educação de Jovens e Adultos (EJA) no decorrer dos anos.

Assim sendo, a metodologia qualitativa torna mais relevante a compreensão que a explicação, pois, baseia-se na construção social da realidade em contextos do cotidiano se servindo da pluralidade na coleta de dados. Já o método bibliográfico do tipo narrativo se utiliza de documentações relacionadas com a vida dos participantes. González, Fernández Camargo (2014). 
Para a coleta dos dados se buscou a nos apanhados históricos a evolução e os recuos baseados em documentos, leis e projetos quanto a Educação de Jovens e Adultos (EJE).

Assim sendo, o objetivo geral buscou evidenciar toda a trajetória da Educação de Jovens e Adultos (EJA) as lutas e as tentativas de mudanças no estado de Rondônia- Brasil.

\section{4.- Discussão dos resultados.}

Figura 2: Gráfico da Atuação de Escolas Estaduais/ Educação de Jovens e Adultos

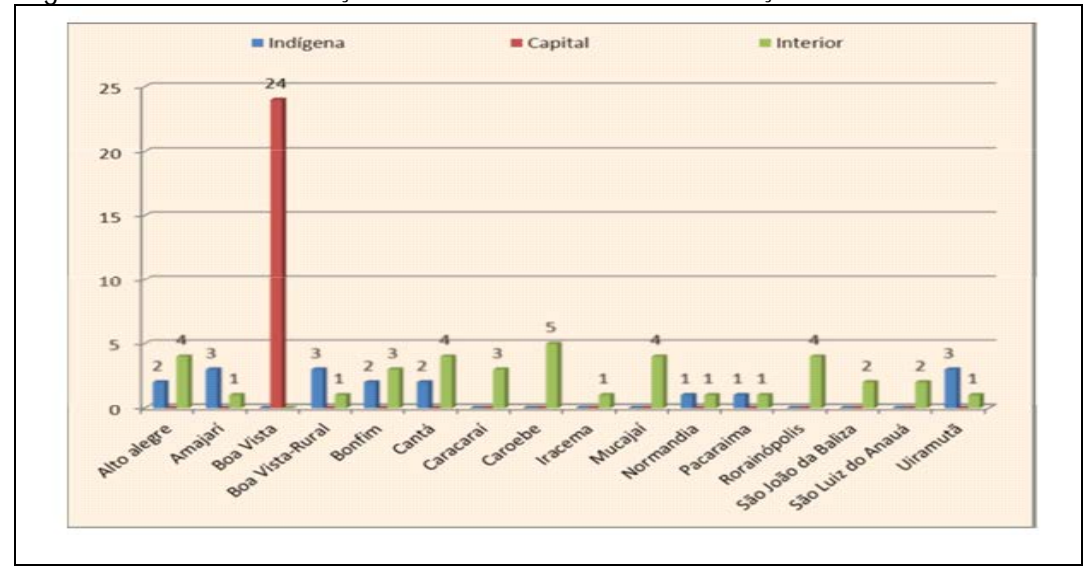

Fonte: Governo do Estado de Roraima (2011).

Segundo a SECD Roraima DIEJA (2011), as escolas da rede estadual atuantes com (EJA), nos municípios e capital, são as seguintes:

Escolas Estaduais com atuação em EJA nas comunidades indígenas:

Escola Estadual Indígena Riachuelo, Escola Estadual Indígena Hermenegildo Sampaio, Escola Estadual Indígena Inácio Mandulao, Escola Estadual Indígena Santa Luzia, Escola Estadual Indígena Tuxaua Raimundo Tenente, Escola Estadual Indígena Lino Augusto da Silva, Escola Estadual Indígena Prof. Genival Thome Macuxi,, Escola Estadual Indígena Ajuricaba; Escola Estadual Indígena $\mathrm{N}^{\mathrm{a}} \mathrm{S}^{\mathrm{a}} \mathrm{da}$ Consolata; Escola Estadual Indígena Tuxaua Otavio Manduca; Escola Estadual Indígena Sizenando Diniz, Escola Estadual Indígena Escola Estadual Indígena Tuxaua Luis Cadete; Escola Estadual Indígena Macuxi; Escola Estadual Indígena Bento Luis; Escola Estadual Indígena Dom Lourenco Zoller, Escola Estadual Indígena Júlio Pereira, Escola Estadual Indígena Koko Izabel Macuxi.

Escolas Estaduais com atuação em EJA na capital:

Escola Estadual América Sarmento Ribeiro. Escola Estadual Antônio Carlos Natalino, Escola Estadual Caranã, Escola Estadual Carlos Drummond de Andrade, Escola Estadual Hildebrando Ferro Bittencourt, Escola Estadual Lobo D’almada, Escola 
Estadual Luiz Ribeiro de Lima, Escola Estadual Luiz Rittler Brito de Lucena, Escola Estadual Maria de Lourdes Neves, Escola Estadual Monteiro Lobato, Escola Estadual Fernando Granjeiro, Escola Estadual Professor Carlo Casadio, Escola Estadual Professor Antônio Ferreira de Souza, Escola Estadual Professor Coema Souto Maior Nogueira, Escola Estadual Professor Jaceguai Reis Cunha, Escola Estadual Professora Maria das Dores Brasil, Escola Estadual Professora Maria Nilce Brandão, Escola Estadual Professor Voltaire Pinto Ribeiro, Escola Estadual Professora Elza Breves de Carvalho, Escola Estadual Professora Maria das Neves Rezende, Escola Estadual Professora Maria Sônia de Brito Oliva, Escola Estadual Professora Vanda da Silva Pinto, Escola Estadual Professora Raimunda Nonata Freita da Silva, Escola Estadual Professora Wanda David Aguiar.

Escolas Estaduais com atuação em EJA nos municípios:

Escola Estadual Delcy Barreto de Souza, Escola Estadual I Desembargador Sadoc Pereira, Escola Estadual Maria Francisca da Costa Moraes, Escola Estadual I Professor Geraldo da Silva Pinto, Escola Estadual I Nilo Jose de Melo, Escola Estadual Argentina Castelo Branco, Escola Estadual Joao Vilena, Escola Estadual São Francisco, Escola Estadual Antônio Augusto Martins, Escola Estadual Jose Aureliano da Costa, Escola Estadual Otília de Sousa Pinto, Escola Estadual Prof. Genira Brito Rodrigues, Escola Estadual Joao Rogelio Schuertz, Escola Estadual Pe Calleri, Escola Estadual Presidente Castelo Branco, Escola Estadual Clovis Nova da Costa, Escola Estadual Dom Pedro I, Escola Estadual Professor Vidal da Penha Ferreira, Escola Estadual Tereza Teodoro de Oliveira, Escola Estadual Dom Pedro II, Escola Estadual Coelho Neto, Escola Estadual Maria Mariselma de Oliveira Cruz, Escola Estadual Nova Esperança, Escola Estadual Padre Jose Monticone, Escola Estadual Mariano Vieira, Escola Estadual Cicero Vieira Neto, Escola Estadual $1^{\circ}$ de Maio, Escola Estadual Fagundes Varela, Escola Estadual Jose de Alencar, Escola Estadual Professora Antônia Tavares da Silva, Escola Estadual Francisco Ricardo Macedo, Escola Estadual Henrique Dias, Escola Estadual Joao Rodrigues da Silva, Escola Estadual Professor Alan Kardec Dantas Haddad, Joaquim Nabuco.

Cabe destacar que em todos os estabelecimentos de ensino da Capital Boa Vista Roraima, são evidenciados altos índices de evasão todos os anos. A marginalização é uma característica que está presente na modalidade EJA em Boa Vista-RR, sendo que esta marca é presente na educação básica e os acompanha ao ensino superior. Dentre as dificuldades dos alunos da EJA, estão presentes as questões de trabalho, a ausência de uma aula centrada nos conhecimentos e experiência do aluno, relacionadas aos saberes teóricos ministrados em sala de aula, e no despreparo do professor que atua na EJA (Franco, 2013).

\section{5.-Conclusão.}

Em virtude dos fatos mencionado a história da Educação de Jovens e Adultos (EJA) é permeada pela trajetória de ações e programas destinados à Educação Básica e, em particular, aos programas de alfabetização para o combate ao analfabetismo, com ações para o público jovem e adultos em todo território nacional. 
No entanto, a principal finalidade da Educação de Jovens e Adultos, conforme previsto na Constituição Federal de outubro de 1988 era garantir o acesso e a permanência ao ensino a todos, inclusive aos jovens e adultos que não tiveram a oportunidade de estudar em idade própria.

Todavia, pode-se perceber que foi a partir da década de 40 que a educação de adultos passou a ser reconhecida e a receber um tratamento particular que se intensificou com as promulgações das Leis de Diretrizes e Bases da Educação Nacional.

Contudo, projetos e planos implantado em Roraima visavam o avanço na educação e a erradicação do analfabetismo os quais foram um tanto precipitados, isso devido a criação de projetos e mais projetos sem se quer ter, o tempo necessário para surtir efeito e, estes eram desmantelados ou trocados por outros projetos. Vale destacar que o movimento de políticas públicas propostas pelos governos no decorrer dos anos, aconteceram pela forte pressão tanto internacional, dos órgãos como a UNESCO e a ONU, tanto quanto nacional com os movimentos populares que beneficiou 0 estado.

Entretanto, no cenário atual, ainda há muito o que se conquistar para almejar as mudanças necessárias de paradigmas alienadores transpor a posta para cidadãos pensantes, atuantes, críticos e ativos para a sociedade latente.

Por fim, é possível verificar que existem, meios para se melhorar a Educação de Jovens e Adultos e como constatado no estado de Roraima este ainda se encontra em batalha decorrente de anos e horas a conquista e em breve espaço de tempo 0 recuo o retrocesso acentuado nos programas que tangem a Educação de Jovens e Adultos.

\section{6.-Referências.}

Cunha, C.M. (1999). Introdução discutindo conceito básico. In Salto para o futuro Educação de Jovens e Adultos. Brasília: Ministério da Educação e Cultura.

Feitoza, R. S. (2008). Movimentos de Educação de Pessoas Jovens e Adultas na perspectiva da Educação Popular no Amazonas. Matrizes históricas, marcos conceituais e impactos políticos. Tese de doutorado 380 p. João Pessoa: Universidade Federal da Paraíba.

Freitas, A.S. (1993). A história Política e administrativa de Roraima de 1943 a 1985. $1^{\mathrm{a}}$ ed. Manaus: Calderado.

Franco, V. (2013). Educação de Jovens e Adultos: uma análise das expectativas dos alunos finalistas da escola Monteiro Lobato em Roraima no ano de 2012, quanto à continuidade dos estudos na educação superior. Dissertação de Mestrado 235 p: Manaus: Universidade Federal do Amazonas. 
González, J.A.T., Fernández, A.H., De Barros, C. (2013). Aspectos fundamentais da pesquisa científica. Granada: Ediciones Adeo.

Haddad, S., Di Pierro, M.C. (2000). Escolarização de jovens e adultos. São Paulo: Revista Brasileira de Educação v.14, n.3, p.108.

Lei de Diretrizes e Bases. (1996). Lei no 9.394, de 20 de dezembro de 1996. Presidência da República. Casa Civil. Brasília: Subchefia para Assuntos Jurídicos.

Roraima-Secad. (2010). Proposta da Rede Pública Estadual Para a Educação de Jovens e Adultos. Boa Vista: Secretaria Estadual de Educação e Cultura.

Santos, H.E.A. (2000). Fatores de crescimento de Roraima, 1970/1998. Dissertação de mestrado 197 p. Porto Alegre: Universidade Federal de Rio Grande do Sul.

Santos, N.P.D. (2004). Políticas Públicas, economia e poder: o Estado de Roraima entre 1970 e 2000. Tese de doutorado 356 p. Belém: Universidade Federal do Pará. 